Bull. Chem. Soc. Ethiop. 2014, 28(1), 67-71.

ISSN 1011-3924

Printed in Ethiopia

DOI: http://dx.doi.org/10.4314/bcse.v28i1.8

(C) 2014 Chemical Society of Ethiopia

\title{
HETEROPOLYACIDES AS GREEN AND REUSABLE CATALYSTS FOR THE SYNTHESIS OF $[3,4-b][1,3,4]$ THIADIAZINES
}

\author{
Fatemeh Hakimi $^{1 *}$, Alireza Hassanabadi ${ }^{2}$, Masoumeh Tabatabaee ${ }^{3}$ and Majid M. Heravi ${ }^{4}$ \\ ${ }^{1}$ Department of Chemistry Payame Noor Univercity, P.O. Box 19395-3697, Tehran, Iran \\ ${ }^{2}$ Department of Chemistry, Zahedan Branch, Islamic Azad University, P.O. Box 98135-978, \\ Zahedan, Iran \\ ${ }^{3}$ Department of Chemistry, Yazd Branch, Islamic Azad University, P.O. Box 89195-155, Yazd, \\ Iran \\ ${ }^{4}$ Department of Chemistry, School of Sciences, Azzahra University, Tehran, Iran
}

(Received October 16, 2012; revised September 25, 2013)

\begin{abstract}
Synthesis of $[3,4-b][1,3,4]$ thiadiazines from the condensation of 4-amino-6-methyl-3-thioxo1,2,4-triazine-5(2H)-one (AMTTO) or 4-amino-1,4-dihydro-5-methyle-1,2,4-triazole-5-thione (AMTT) with phenacyl bromide in the presence of a catalytic amount of various heteropolyacids (HPAs) under refluxing conditions is reported.
\end{abstract}

KEY WORDS: Heteropolyacids, Phenacyl bromide, Heterocyclization, Thiadiazines

\section{INTRODUCTION}

1,2,4-Triazolo[3,4- $b][1,3,4]$ thiadiazines and 1,2,4-triazino[3,4-b][1,3,4]thiadiazines constitute two classes of compounds interesting from view points of chemical reactivity [1-4] and biological activity. Antibacterial [5-7] and anti-inflammatory [8], antivirial [9, 10], antitumor [11, 12], and antifungal [13] activity, as well as interesting CNS depressing activity [14] has been reported for certain of the derivatives. Due to their importance, the synthesis of these compounds is interested for the discovery of improved protocols towards milder and high yielding approaches.

It was shown that some heteropolyanions exhibited interesting catalytic properties as green and eco-friendly catalysts for both redox and/or acid-base type reactions in industrial applications $[15,16]$. Examples of acid-base type catalysis are: cracking and alkylation of hydrocarbons, dehydration of alcohols, electrophilic addition of alcohols to olefines, etc [17, 18]. Heteropolyacids, both solid and in solution, are compared with the strongest mineral acids exhibiting even strength higher than mineral acids, and are comparable to that to the so-called superacids [19]. Heteropolyacids (HPAs) are well defined molecular clusters that are remarkable for their molecular and electronic structural diversity and their significance is quite diverse in many areas, e.g., catalysis, medicine, and materials science [20, 21]. HPAs are complex proton acid that incorporate polyoxometalate anions (heteropolyanions) having metal-oxygen octahedra as the basic structural units and catalysis by them is a field of increasing importance [22-30]. Heteropolyacids as solid acid catalysts are green with respect to corrosiveness, safety, quantity of waste, and separ ability and it is well known that the use of heteropolyacid catalysts for organic synthesis reactions can give a lot of benefits. Heteropolyacids are widely used in variety of acid catalyzed reactions [31-38]. As part of our current studies on the development of new routes in organic synthesis [39-41], we report an efficient one-pot synthesis of the [1,3,4][3,4$b]$-thiadiazine derivatives, employing readily available starting materials.

*Corresponding author. E-mail: fatemeh.hakimi@yahoo.com 


\section{EXPERIMENTAL}

\section{Materials and instruments}

Melting points were determined with an Electrothermal 9100 apparatus. Elemental analysis were performed using a Costech ECS 4010 CHNS-O analyzer at analytical laboratory of Islamic Azad University Yazd branch. Mass spectra were recorded on a FINNIGAN-MAT 8430 mass spectrometer operating at an ionization potential of $70 \mathrm{eV}$. IR spectra were recorded on a Shimadzu IR-470 spectrometer. ${ }^{1} \mathrm{H}$ and ${ }^{13} \mathrm{C}$ NMR spectra were recorded on Bruker DRX-500 Avance spectrometer at solution in $\mathrm{d}_{6}$-DMSO using TMS as internal standard. The chemicals used in this work were purchased from Fluka (Buchs, Switzerland) and were used without further purification. Heteroployacids (HPAs) were prepared as previously described in the literature [41, 42] and also the compounds AMTTO and AMTT was prepared as previously described in the literature[43-45].

\section{General procedure for preparation of compounds 6}

A mixture of AMTTO or AMTT $(2 \mathrm{mmol})$, Phenacyl bromide $(2 \mathrm{mmol})$ and heteropolyacid $0.04 \mathrm{~g}$ was added to a magnetically stirred solution of sodium( $0.046 \mathrm{~g}, 2 \mathrm{mmol})$ in ethanol (30 $\mathrm{mL}$ ). The reaction mixture was stirred for $45 \mathrm{~min}$ under refluxing conditions. The resulting precipitate was collected by filtration on a Buchner funnel and washed with $10 \mathrm{~mL}$ of cold ethanol to afford the pure title compounds $\mathbf{3}$ or $\mathbf{6}$.

\section{Catalyst reusability}

At the end of the reaction, the catalyst could be recovered by a simple filtration. The recycled catalyst could be washed with dichloromethane and used in a second run of the reaction process. The results of the first and subsequent experiments were almost consistent in yields.

The selected spectral data

3-methyl-6-phenyl-7H-[1,2,4]triazolo[3,4-b][1,3,4]thiadiazin (6).Pale orange crystal, m.p. 195 $-197{ }^{\circ} \mathrm{C}$, IR $(\mathrm{KBr})\left(v_{\max } \mathrm{cm}^{-1}\right): 1705,1560$. Analyses: calcd. for $\mathrm{C}_{11} \mathrm{H}_{10} \mathrm{~N}_{4} \mathrm{~S}: \mathrm{C}, 57.37 ; \mathrm{H}, 4.38$; $\mathrm{N}, 24.33 \%$. Found: C, 57.48; H, 4.25; N, 24.41. MS (m/z, \%): $230(5) .{ }^{1} \mathrm{H}$ NMR (500 MHz, $\mathrm{d}_{6}-$ DMSO): $\delta 2.49\left(3 \mathrm{H}, \mathrm{s}, \mathrm{CH}_{3}\right), 4.38\left(2 \mathrm{H}, \mathrm{s}, \mathrm{SCH}_{2}\right), 7.56-8.02\left(5 \mathrm{H}, \mathrm{m}, \mathrm{C}_{6} \mathrm{H}_{5}\right) \mathrm{ppm} .{ }^{13} \mathrm{C} \mathrm{NMR}$ (125.8 MHz, d ${ }_{6}$-DMSO): $\delta 17.41\left(\mathrm{CH}_{3}\right), 33.09\left(\mathrm{SCH}_{2}\right), 129.32,130.84,132.28,134.72,148.42$, 150.19 and $170.41(7 \mathrm{C}) \mathrm{ppm}$.

\section{RESULTS AND DISCUSSION}

Herein, we wish to report the condensation of 4-amino-6-methyl-3-thioxo-1,2,4-triazine-5 $(2 H)$ one (AMTTO) or 4-amino-1,4-dihydro-5-methyle-1,2,4-triazole-5-thione (AMTT) with phenacyl bromide in the presence of sodium ethoxide under refluxing conditions and the use of Keggin type heteroployacids (HPAs), including $\mathrm{H}_{3}\left[\mathrm{PW}_{12} \mathrm{O}_{40}\right], \mathrm{H}_{4}\left[\mathrm{SiW}_{12} \mathrm{O}_{40}\right], \mathrm{K}_{7}\left[\mathrm{PMo}_{2} \mathrm{~W}_{9} \mathrm{O}_{40}\right]$ and $\mathrm{H}_{3}\left[\mathrm{PW}_{12} \mathrm{O}_{40}\right] \cdot 6 \mathrm{H}_{2} \mathrm{O}-\mathrm{SiO}_{2}$ (Scheme 1). 


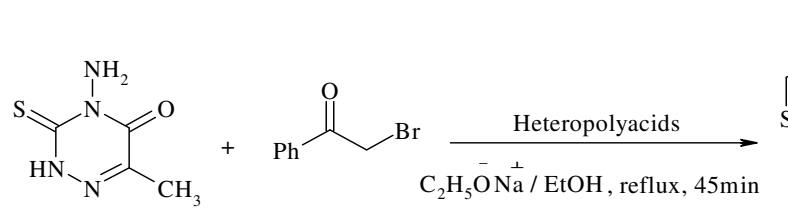<smiles>Cc1nnc2n(c1=O)N=C(c1ccccc1)CS2</smiles><smiles>Cc1n[nH]c(=S)n1N</smiles><smiles>CCO[N+](=O)[O-]</smiles>

AMTT<smiles>Cc1nnc2n1N=C(c1ccccc1)CS2</smiles>

Scheme 1. Condensation of AMTTO or AMTT with phenacyl bromide in the presence of heteroployacids (HPAs) as catalyst.

The compounds 3 was characterised by NMR, IR spectroscopy and elemental analysis [40]. Compounds 6 was new and its structure was deduced by elemental and spectral analysis. The ${ }^{1} \mathrm{H}-\mathrm{NMR}$ spectrum of compound $\mathbf{6}$ exhibited one sharp singlet signal readily recognized for protons of the methyl $(\delta=2.49 \mathrm{ppm})$, and a single signal was observed at $4.38 \mathrm{ppm}$ for methylene group. The aromatic protons resonated between 7.56-8.02 ppm. The ${ }^{13} \mathrm{C}-\mathrm{NMR}$ spectrum of compound 3 shows nine distinct signals, which is consistent with the proposed structure. The mass spectrum of 6 displayed the molecular ion peak at $\mathrm{m} / \mathrm{z}=230$. The IR spectrum of compound $\mathbf{6}$ also supported the suggested structure.

It is reasonable to assume that compound $\mathbf{6}$ results from the initial addition of AMTT to phenacyl bromide to intermediate $\mathbf{4}$. Heterocycization of $\mathbf{4}$ can lead to the formation of $\mathbf{6}$ not $\mathbf{5}$ according to the spectral data, ${ }^{1} \mathrm{H}-\mathrm{NMR}$, it was identified as the structure $\mathbf{6}$. By elucidation of the structure, it can be assumed that HPA catalyzed cyclization of $\mathbf{4}$ to $\mathbf{6}$ proceeds via direct attack of the amino group to $\mathrm{C}=\mathrm{O}$ phenyl bond activated by proton coordination of HPA, then with elimination $\mathrm{H}_{2} \mathrm{O}$ can occurred 6 (Scheme 2).

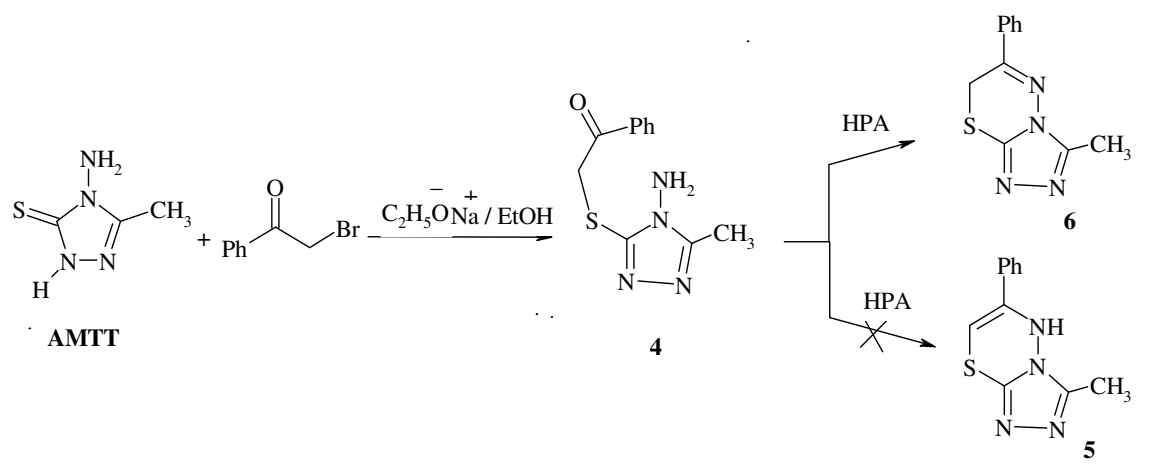

Scheme 2. Suggested mechanism for formation of compound $\mathbf{3}$.

In order to determine the optimum quantity of heteropolyacids, the condensation of (AMTTO) or (AMTT) with phenacyl bromide in the presence of sodium ethoxide under 
refluxing conditions (Table 1), heteropolyacids of $0.04 \mathrm{~g}$ gave an excellent yield in $45 \mathrm{~min}$ (Table 1, entry 12). To study the scope of the reaction, a series of heteropolyacids were applied. As shown in Table $1, \mathrm{H}_{3}\left[\mathrm{PW}_{12} \mathrm{O}_{40}\right] \cdot 6 \mathrm{H}_{2} \mathrm{O}-\mathrm{SiO}_{2}$ showed the highest activity and gave better yields (Table 1, entry 12).

Table 1. Effect of different reaction time and amount of various heteropolyacids on synthesis of $[3,4-$ $b][1,3,4]$ thiadiazines.

\begin{tabular}{|c|c|c|c|c|}
\hline \multirow[t]{2}{*}{ Entry } & \multirow[t]{2}{*}{ Catalyst (g) } & \multirow[t]{2}{*}{ Time (min) } & \multicolumn{2}{|c|}{ Yield $^{\mathrm{a}}(\%)$} \\
\hline & & & Product 3 & Product 6 \\
\hline 1 & $\mathrm{H}_{3}\left[\mathrm{PW}_{12} \mathrm{O}_{40}\right](0.01)$ & 180 & 62 & 60 \\
\hline 2 & $\mathrm{H}_{4}\left[\mathrm{SiW}_{12} \mathrm{O}_{40}\right](0.01)$ & 180 & 60 & 60 \\
\hline 3 & $\mathrm{~K}_{7}\left[\mathrm{PMo}_{2} \mathrm{~W}_{9} \mathrm{O}_{40}\right](0.01)$ & 180 & 70 & 72 \\
\hline 4 & $\mathrm{H}_{3}\left[\mathrm{PW}_{12} \mathrm{O}_{40}\right] .6 \mathrm{H}_{2} \mathrm{O}-\mathrm{SiO}_{2}(0.01)$ & 180 & 88 & 87 \\
\hline 5 & $\mathrm{H}_{3}\left[\mathrm{PW}_{12} \mathrm{O}_{40}\right](0.02)$ & 120 & 70 & 69 \\
\hline 6 & $\mathrm{H}_{4}\left[\mathrm{SiW}_{12} \mathrm{O}_{40}\right](0.02)$ & 120 & 67 & 64 \\
\hline 7 & $\mathrm{~K}_{7}\left[\mathrm{PMo}_{2} \mathrm{~W}_{9} \mathrm{O}_{40}\right](0.02)$ & 120 & 74 & 73 \\
\hline 8 & $\mathrm{H}_{3}\left[\mathrm{PW}_{12} \mathrm{O}_{40}\right] .6 \mathrm{H}_{2} \mathrm{O}-\mathrm{SiO}_{2}(0.02)$ & 120 & 84 & 82 \\
\hline 9 & $\mathrm{H}_{3}\left[\mathrm{PW}_{12} \mathrm{O}_{40}\right](0.04)$ & 45 & 79 & 76 \\
\hline 10 & $\mathrm{H}_{4}\left[\mathrm{SiW}_{12} \mathrm{O}_{40}\right](0.04)$ & 45 & 75 & 73 \\
\hline 11 & $\mathrm{~K}_{7}\left[\mathrm{PMo}_{2} \mathrm{~W}_{9} \mathrm{O}_{40}\right](0.04)$ & 45 & 80 & 79 \\
\hline 12 & $\mathrm{H}_{3}\left[\mathrm{PW}_{12} \mathrm{O}_{40}\right] .6 \mathrm{H}_{2} \mathrm{O}-\mathrm{SiO}_{2}(0.04)$ & 45 & 95 & 93 \\
\hline 13 & $\mathrm{H}_{3}\left[\mathrm{PW}_{12} \mathrm{O}_{40}\right](0.08)$ & 30 & 80 & 75 \\
\hline 14 & $\mathrm{H}_{4}\left[\mathrm{SiW}_{12} \mathrm{O}_{40}\right](0.08)$ & 30 & 76 & 74 \\
\hline 15 & $\mathrm{~K}_{7}\left[\mathrm{PMo}_{2} \mathrm{~W}_{9} \mathrm{O}_{40}\right](0.08)$ & 30 & 78 & 76 \\
\hline 16 & $\mathrm{H}_{3}\left[\mathrm{PW}_{12} \mathrm{O}_{40}\right] .6 \mathrm{H}_{2} \mathrm{O}-\mathrm{SiO}_{2}(0.08)$ & 30 & 90 & 89 \\
\hline
\end{tabular}

${ }^{\mathrm{a}}$ Isolated yield.

\section{CONCLUSION}

In summary, we have shown that heteroployacids (HPAs) as green and reusable catalysts for the synthesis of $[3,4-b][1,3,4]$ thiadiazines have advantages in condensation reaction of AMTTO or AMTT with phenacyl bromide such as shorter reaction times, simple work-up, and affords good yield. The present method does not involve any hazardous organic solvent. Therefore, this procedure could be classified as green chemistry.

\section{REFERENCES}

1. Invidiata, F.P.; Furno, G.; Lampronti, L.; Semoni, D.J. J. Heterocyclic Chem. 1997, 34, 1255.

2. Heindel, N.D.; Reid, J.R. Org. Prep. Proced. Int. 1981, 13, 123.

3. Chadha, V.K. J. Indian Chem. Soc. 1978, 55, 817.

4. Chadha, V.K.; Sharma, G.R. J. Indian Chem. Soc. 1980, 57, 1112.

5. Mahan, J.; Alajarin, G.S. R. J. Chem. Soc., Perkin Trans I 1987, 1853.

6. Omar, A.M.M.E.; Aboulmafe, O.M. J. Heterocyclic Chem. 1986, 23, 1339.

7. Ghannoum, M.A.; Eweiss, N.F.; Bahajaj, A.A.; Quereshi, M.A. Microbios. 1983, 37, 151.

8. Rasad, A.R.; Ramalengamat, T.; Ras, A.B.; Drawn, P.W.; Sattur, P.B. Indian J. Chem. 1986, 26B, 556.

9. Falke, D.; Rada, B. Acta Virol. 1970, 14, 115.

10. Sidwell, R.W.; Dixon, G.J.; Schabel, F.M. J. Appl. Microbiol. 1968, 16, 370. 
Heteropolyacides as green and reusable catalysts for synthesis of [3,4-b][1,3,4] thiadiazines 71

11. Creasey, W.A.; Fink, M.E.; Handschurnacker, R.E.; Calabresi, P. Cancer Res. 1963, 23, 444.

12. Walters, T.R.; Aur, R.J.; Hernandez, A.K.; Veetli, T.; Penkel, D. Cancer 1963, 29, 1057.

13. Malolcsy, G. Acta Phytopathol. 1966, 1, 245.

14. Deshmukh, A.A.; Mody, M.K.; Ramalengant, T.; Sattur, P.B. Indian J. Chem. 1985, 25B, 793.

15. Yadav, G.D.; Bhagat, R.D. J. Mol. Catal. 2005, 235, 98.

16. Imamura, K.; Tano, K.; Kobeppn, S. Jpn. Kokai Tokkyo Koho, JP Patent, 1087811, 1998.

17. Misono, M. Catal. Rev. Sci. Eng. 1987, 29, 269.

18. Izumi, Y.; Urabe, K.; Onaka, M. Zeolite, Clay and Heteropoly Acid inOrganic Reactions, Kodansha/VCH: Tokyo; 1992; p 99.

19. Misono, M.; Okuhara, T. Chemtechnology 1993, 23, 23.

20. Pope, M.T.; Muller, A. Angew. Chem. Int. Ed. Engl. 1991, 30, 34.

21. Pope, M.T.; Muller, A. Polyoxometalates: from Platonic Solids to Anti-Retroviral Activity, Kluwer Academic Publishers: Dordrecht, Netherlands; 1994, p1.

22. Misono, M., Catal. Rev. Sci. Eng. 1998, 30, 339.

23. Vázquez, P.G.; Blanco, M.N.; Cáceres, C.V. Catal. Lett. 1999, 60, 205.

24. Mukai, S.R.; Sugiyama, T.; Tamon, H. Appl. Catal. A 2003, 256, 99.

25. D’allessandro, O.; Sathicq,G.; Palermo,V.; Sanchez, L.M.; Thomas, H.; Vázquez, P.; Constantieux, T.; Romanelli. G. Curr. Org. Chem. 2012, 16, 2763.

26. Bamoharram, F.F.; Heravi, M.M.; Roshani, M.; Tavakoli, N. J. Mol. Catal. A: Chem. 2006, 252, 219.

27. Heravi, M.M.; Sadjadi, S.; Oskooie, H.A.; Hekmat Shoar, R.; Bamoharram, F.F. Molecules 2007, 12, 255.

28. Heravi, M.M.; Behbahani, F.K.; Bamoharram. F.F. J. Mol. Catal. A: Chem. 2006, 253, 16.

29. Heravi, M.M.; Ranjbar, L.; Derikvand, F.; Bamoharram, F.F. Catal. Commun. 2007, 8, 289.

30. Bamoharram, F.F.; Heravi, M.M.; Roshani, M.; Jahangir, M.; Gharib, A. J. Appl. Catal. A: Gen. 2006, 302, 42.

31. Anastas, P.T.; Warner, J.C. Green Chemistry, Theory and Practice, Oxford University Press: Oxford; 1998; p 1.

32. Clark, J.H. Green Chem. 1999, 1, 1.

33. Hu, C.; Hashimoto, M.; Okuhara, T.; Misono, M. J. Catal. 1993, 143, 437.

34. Okuhara, T.; Kasai, A.; Misono, M. Catalyst 1980, 22, 226.

35. Yamada, T. Peterotech (Tokyo), 1990, 13, 627.

36. Okuhara, T.; Nishimura, T.; Ohashi, K.; Misono, M. Chem. Lett. 1990, 1201.

37. Okuhara, T.; Nishimura, T.; Ohashi, K.; Misono, M. Chem. Lett. 1995, 155.

38. Aoshima, A.; Tonomura, S.; Yamamatsu, S. Adv. Technol. 1990, 2, 127.

39. Heravi, M.M.; Ajami, D.; Ghassemzadeh, M. Synth. Commun. 1999, 29, 1013.

40. Heravi, M.M.; Rajabzadeh, G.; Rahimizadeh, M.; Bakavoli M.; Ghassemzadeh, M. Phosphorus Sulfur Silicon 2001, 170, 205.

41. Pope, M.T. Heteropoly and Isopoly Oxometalates, Springer-Verlag: Washington, D.C.; $1983 ; \mathrm{p} 1$.

42. Massart, R.; Contant, R.; Fruchart, J.M.; Ciabrini, J. P.; Fournier, M. Inorg. Chem. 1977, 16, 2916.

43. Metze, R.; Meyer, S. Chem. Ber. 1957, 90, 481.

44. Dornow, A.; Menzel, H.; Marx, P. Chem. Ber. 1964, 97, 2173.

45. Beyer, H.; Kröger, C.F. Chem. Ber. 1960, 637, 135. 